\title{
Derleme/Review
}

\section{Alzheimer Hastalarında Kullanılan İlaç Dışı Tedavi Yöntemleri}

\section{Non-Drug Treatment Methods Used in Alzheimer Patients}

\author{
Canan Bozkurt $^{1}$ (iD) Ayfer Karadakovan ${ }^{2}$ \\ ${ }^{1}$ Bandırma Onyedi Eylül Üniversitesi Sağlık Bilimleri Fakültesi Hemşirelik Bölümü İç Hastalıkları Hemşireliği ABD, Balıkesir, TÜRKIYE \\ ${ }^{2}$ Ege Üniversitesi Hemşirelik Fakültesi İç Hastalıkları Hemşireliği ABD, Bornova, İzmir, TÜRKIYYE
}

Gelis tarihi/ Date of receipt: 30/07/2020 Kabul tarihi/ Date of acceptance:07/12/2020

(C) Ordu University Faculty of Health Sciences, Department of Nursing, Turkey, Published online: 31/12/2020

\begin{abstract}
ÖZ
Alzheimer hastalığı, hipokampus, serebral korteks ve subkortikal alanlarda senil plaklar ve nörofibriler düğümlerin varlığ ile karakterize en sık görülen nörodejeneratif hastalıktır. Hastalığın erken aşamaları klasik olarak bellekteki zayıflama ile ilişkilidir. Hastalığın erken evresinde bireyler kelime bulmakta, yeni insanların isimlerini hatırlamakta ve sosyal/iş görevlerinde zorluk yaşamaktadırlar. Beraberinde son günlerde okuduğu yazıyı unutma ve nesneleri yanlış yerleştirme gibi sorunlar görülebilmektedir. Hastalık ilerledikçe orta evrede önemli olayları veya kişisel anıları unutmak, sosyal geri çekilme, adres veya telefon numaralarını hatırlayamama, zaman ve yer oryantasyonunda bozulma, mevsime/ortama uygun kıyafet seçememe, uyku düzeni değişiklikleri, gezinme veya kaybolma riski, kişilik veya davranış değişiklikleri (şüphe, dürtüsellik, sanrılar ve tekrarlayan davranışlar) görülmektedir. Alzheimer hastalığının neden olduğu bu sorunların sona erdirilmesi için erken tanı, tedavi ve özellikle de önlenmesine yönelik çeşitli yaklaşımlara gereksinim vardır. Teknolojinin de ilerlemesiyle dünyada ve ülkemizde çalışmaların artmasına rağmen hastalığın önlenmesi ve kesin tedavisi henüz mümkün olmamaktadır. Ancak Alzheimer hastalığına sahip yaşlı bireylerin günlük yaşam aktivitelerine katılımı ve yaşam kalitesinin artırılabilmesi için ilaç tedavisinin yanı sıra özellikle hastalığın belirtilerini azaltmakta ilaç dışı yöntemler de uygulanmaktadır.

$\mathrm{Bu}$ derleme, farmakolojik tedavinin yanı sıra Alzheimer hastalarının semptomlarını azaltmak ve yaşam kalitesini artırmak için kullanılabilecek geleneksel ve destekleyici yöntemlerin hemşireler ve diğer sağlık profesyonellerine yol göstermesini amaçlamaktadır.
\end{abstract}

Anahtar Kelimeler: Alzheimer hastalığı, bilişsel durum, tamamlayıcı terapi

\begin{abstract}
Alzheimer's disease is the most common neurodegenerative disease characterized by the presence of senile plaques and neurofibrillary nodes in the hippocampus, cerebral cortex and subcortical areas. The early stages of the disease are classically associated with a weakening of memory. In the early stage of the disease, individuals find words, remember the names of new people, and have difficulties in their social / work duties. Moreover, problems such as forgetting the text he has read recently and placing the objects incorrectly can be seen. As the disease progresses, forgetting important events or personal memories in the middle stage, social withdrawal, not remembering addresses or phone numbers, disruption in time and location orientation, choosing clothes suitable for the season / environment, changes in sleep patterns, risk of wandering or loss, personality or behavior changes (suspicion, impulsivity, delusions, and repetitive behaviors). Various approaches to early diagnosis, treatment and especially prevention are needed to end these problems caused by Alzheimer's Disease. Despite the increase in the world and our country with the advancement of technology, the prevention and definitive treatment of the disease is not yet possible. However, in addition to drug therapy, non-drug methods are also used to reduce the symptoms of the disease in order to increase the quality of life and to participate in daily life activities of elderly individuals with Alzheimer's Disease.

The aim of this review is to guide nurses and other health professionals as well as pharmacological treatment, as well as traditional and supportive methods that can be used to reduce the symptoms of Alzheimer's patients and improve their quality of life.
\end{abstract}

Keywords: Alzheimer's disease, cognitive status, complementary therapy

ORCID IDs of the authors: CB: 0000-0001-8034-4062; AK: 0000-0002-7225-6860

Sorumlu yazar/Corresponding author: Arş. Gör. Canan Bozkurt

Bandırma Onyedi Eylül Üniversitesi Sağlık Bilimleri Fakültesi Hemşirelik Bölümü İç Hastalıkları Hemşireliği ABD, Balıkesir, TÜRKIYE e-posta/e-mail: cbozkurt@bandirma.edu.tr

Atıf/Citation: Bozkurt C, Karadakovan A. (2020). Alzheimer hastalarında kullanılan ilaç dışı tedavi yöntemleri. Ordu Üniversitesi Hemşirelik Çalı̧̧maları Dergisi, 3(3), 329-337. DOI: 10.38108/ouhcd.775116 


\section{Giriş}

Türkiye'de ve dünyada yaşlı nüfusun artması ile birlikte karşımıza çıkan Alzheimer Hastalığı (AH), geri döndürülemez bilişsel işlev kaybına neden olan dejeneratif bir hastalıktır ve demansin en yaygın nedenidir (\%60-80) (Alzheimer's Association, 2020).

Dünya Alzheimer Raporu'na göre (2015) demans prevalansı Kuzey Afrika/Orta Doğu'da \%8,7, Latin Amerika'da \%8,5, Orta Avrupa'da \%4,7'dir. Diğer bölgeler kabaca \%5,6 ile \%7,6 arasinda değişmektedir. Bu rapora göre 2015 yılında 46,8 milyon kişinin demansla yaşadığ 1,2030 yılında bu sayının 74,7 milyon, 2050 y1lında ise 131,5 milyon olacağ1 ön görülmektedir. Ayrıca, demans ile yaşayan bireylerin \%58'inin düşük veya orta gelirli ülkelerde olduğu ve bu oranın 2050 yılına kadar $\% 71$ 'e yükselmesinin beklendiği de belirtilmiştir. Sadece Amerika Birleşik Devletleri'nde (ABD) 2015 y1lında tahmini 5,3 milyon bireyin AH olduğu, erken başlangıçlı (60 yaş altı) AH olan birey sayısının ise tahmini 200.000 olabileceği öne sürülmüştür (World Alzheimer Report, 2015). Ülkemizde ise AH'na ilişkin net bir veri olmamakla birlikte 65 yaş ve üzeri yaşlı sayısının Türkiye İstatistik Kurumu (TÜIK) verilerine göre (2017) yaklaşık yedi milyon olduğu ve Türkiye Alzheimer Derneğinin (2019) 600.000 AH olduğunu belirttiği düşünüldügünnde ülkemizde bu oran yaklaşık \%8,5 olarak karşımıza çıkmaktadır (TÜiK, 2017).

Hastalık Kontrol ve Önleme Merkezleri (CDC) verilerine göre 2017 y1lında $\mathrm{AH}$, ABD'de ölüm siralamasinda altıncı sirada yer alırken (erkeklerde $\% 2,6$, kadınlarda \%6,1); Türkiye'de 2015 y1lında erkeklerde \%3,5, kadınlarda ise \%5,2 olarak kayıtlara geçmiştir (CDC, 2017; TÜIK, 2017). 2000-2015 y1lları arasında, inme, kalp hastalığ1 ve prostat kanserinden kaynaklanan ölümler azalırken, AH'na bağlı ölümler \%123 artmıştır (Alzheimer's Association, 2018). Yaş ilerledikçe AH'ndaki bu oranların daha da artacak olmas1 göz önüne alındığında bir halk sağlığı sorunu olmakta; tıbbi, maddi, sosyal ve kamusal açıdan büyük sorunlar oluşturmaktadır.

AH'nın bireye, bakım vericilere ve sağlık kurumlarına olan yükünün yanında kamusal anlamda devletlere de mali anlamda ciddi harcamalara neden olmaktadır. AH'nın ve diğer demans tiplerinin 2015 yılında ABD'de yıllık 226 milyar dolara mal olduğu bildirilmektedir (Sahyouni et al., 2016). Güncel verilere bakıldığında ise ABD'deki tüm $\mathrm{AH}$ ve diğer demans tiplerine sahip bireyler için 2020 yılında bu tutarın resmi olmayan açıklamaya göre 305 milyar dolar olduğu tahmin edilmektedir (Alzheimer's Association, 2020).

Hastalığın ismini aldığı kişi olan psikiyatrist ve nöropatolog Dr. Alois Alzheimer, hastalıkla 1901 yılında 51 yaşında evde kendine bakamayan ve tüm yardımları reddeden bir hasta olan Auguste Deter ile çalıştığ 1 klinikte karşılaşmaktadır. Yapılan muayenede hastada yönelim ve bellek bozukluğu saptanmış ve hastaneye yatırılmıştır. Yazma ve okuma zorluğu olduğu fark edilen hastanın belirtileri zamanla ilerlemiş, halüsinasyonlar ve diğer bilişsel işlevlerinde bozulmalar ortaya çıkmıştır. Dr. Alzheimer'ın o dönem kliniği bırakıp başka bir şehre taşınmasına rağmen Auguste Deter'in 1906 yılında vefat ettiğini öğrenmesi sonucu eski kliniğinden hastanın klinik kayıtlarını ve otopsi yapmak için beynini istemiştir. Mikroskobik olarak hastanın beynini incelediğinde Dr. Alzheimer, korteksin normale göre inceldiğini ve iki anormal bulgu tespit etmiştir. Birinci bulgu, daha önceleri yaşliların beyinlerinde de saptanan senil plaklar, ikincisi ise o dönemde ilk defa kullanılan gümüş boya ile boyanan nörofibriller dügümmler olduğudur. Nörofibriller düğümlerin daha önce hiç tanımlanmaması Dr. Alzheimer için yeni bir hastalığa işaret etmiştir. $\mathrm{Bu}$ hastalığı 1906 y1linda yapılan bir kongrede "Serebral Korteksin Özgün Bir Hastalığı” adıyla sunmuştur. Kongrede ilgi çekmeyen bu hastalığa Alzheimer ismini veren kişi ise Dr. Alzheimer'in klinik şefi olan Dr. Emil Kraepelin'dir. Dr. Kraepelin 1910 yılında yayımlanan Klinik Psikiyatri kitabının sekizinci baskısında "Senil Beyin Hasarı" başlığından sonra "Alzheimer Hastalığı" terimini kullanmıştır (Amin et al., 2019; Sahyouni et al., 2016; Selekler, 2010).

$\mathrm{AH}$, hipokampus, serebral korteks ve subkortikal alanlarda senil plaklar ve nörofibriller düğümlerin varlığı ile karakterize en s1k görülen nörodejeneratif hastalıktır (Amin et al., 2019). Frontal lobun dil, hafıza, soyut düşünce, planlama, sorun çözme, sosyal katılım, entelektüel kapasite gibi bilişsel işlevlerde rol aldığı düşünüldüğünde, AH'nda meydana gelen bu fizyopatolojik süreç bilişsel işlevlerde ilerleyici bir yıkıma neden olmaktadır. Ancak her bellek kaybının meydana gelmesi $\mathrm{AH}$ olduğu anlamina gelmemektedir. Bireylerin yaşlandıkça bazı bellek kayıplarının meydana gelmesi (isim unutma, anahtarın yerini hatırlamama gibi) normal kabul edilebilmektedir. Bununla birlikte, AH'nda görülen bellek değişiklikleri çok 
daha dramatiktir, geçici değildir ve zamanla daha da kötüleşmektedir (Amin et al., 2019; Sahyouni et al., 2016). Hastalığın erken aşamaları klasik olarak bellekteki zayıflama ile ilişkilidir. Hastalığın erken evresinde bireyler kelime bulmakta, yeni insanların isimlerini hatırlamakta ve sosyal/iş görevlerinde zorluk yaşamaktadırlar. Beraberinde son günlerde okuduğu yazıyı unutma ve nesneleri yanlış yerleştirme gibi sorunlar görülebilmektedir. Hastalık ilerledikçe orta evrede önemli olayları veya kişisel anıları unutmak, sosyal geri çekilme, adres veya telefon numaralarını hatırlayamama, zaman ve yer oryantasyonunda bozulma, mevsime/ortama uygun kıyafet seçememe, uyku düzeni değişiklikleri, gezinme veya kaybolma riski, kişilik veya davranış değişiklikleri (şüphe, dürtüsellik, sanrılar ve tekrarlayan davranışlar) görülmektedir. Orta evrede bellek sorunları bilindik yerlerde kaybolmak veya mekânsal ilişkileri yanlış yorumlamak gibi uzamsal farkındalıkta bir bozulma söz konusudur. $\mathrm{Bu}$ da yaşlı birey için normal yollarda yürümeyi veya bildiği çevrede gezinmeyi dahi zorlaştırmaktadır. Yönelim bozukluğu ve mekânsal farkındalık kaybına ek olarak bu bellek kayıpları, konuşma rahatsızlıkları ve beraberinde etkili iletișim kurmayı zorlaștırmaktadır. Birçok birey, sözlü anlatmaya çalıștıkları olaylarda doğru kelimeyi bulamadıkları için "dilinin ucunda fenomeni" yaşamaktadırlar. Hastalığın ileri evresinde ise yaşlı bireyin günlük yaşam aktivitelerini gerçekleştirmek için tam zamanlı yardıma gereksinimi vardır. Nedeni ise yürüme, oturma ve ileriki zamanlarda yutma gibi fiziksel işlevlerinin bozulmasıdır (Sahyouni et al., 2016). Bu durumlar yaşlı bireyin özellikle enfeksiyon ve pnömoniye karşı açık hale gelmesine neden olmakta ve yaşamını tehdit etmektedir.

AH'nın neden olduğu bu sorunların sona erdirilmesi için erken tanı, tedavi ve özellikle de önlenmesine yönelik çeșitli yaklaşımlara gereksinim vardır. Teknolojinin de ilerlemesiyle dünyada ve ülkemizde çalışmaların artmasına rağmen hastalığın önlenmesi ve kesin tedavisi henüz mümkün olmamaktadır. Ancak AH'na sahip yaşıı bireylerin günlük yaşam aktivitelerine katılımı ve yaşam kalitelerinin artırılabilmesi için ilaç tedavilerinin yanı sıra özellikle hastalık belirtilerinin azaltılmasında ilaç dışı tedavi yöntemleri de uygulanmaktadir.

\section{İlaç Dıșı Tedavi Yöntemleri}

İlaç dışı yöntemler demans ve AH'nda psikososyal semptomlara yönelik olarak tıbbi tedaviyle birlikte kullanılan destekleyici tedavi yöntemleridir (Keogh et al., 2019). AH'nda görülen psikososyal belirtiler; bilişsel olarak incelendiğinde bellekte ve bilişsel işlevlerde azalma, yakın geçmişi hatırlayamama, yeni bir bilgiyi öğrenememe, yeni hafıza oluşturamama gibi; davranışsal olarak incelendiğinde ise depresyon, agresyon, ajitasyon, hezeyan, sosyal olarak geri çekilme gibi belirtiler olarak ortaya çıkmaktadır (Selekler, 2010). Farmakolojik olarak uygulanan tıbbi tedavinin yanında destekleyici olarak kullanılan ilaç dışı uygulamalar, bireyin olumsuz belirtilerini azaltması ve yaşam kalitesini arttırması açısından Amerikan Psikiyatri Birliği Kılavuzu'nda da önerilmektedir. Ancak bu yöntemlerin uygulandığ 1 mevcut araştırmalar, hizmet ortamı, spesifik davranış, hastalık evresi, bakıcı ve hasta profili için hangisinin en iyi sonuç verdiğini kesin olarak göstermemektedir. Yapılan bir dizi yüksek kaliteli meta-analiz, sistematik gözden geçirme ve randomize kontrollü çalışmaların yayınlanması, psikososyal müdahalelerin biliş, işlev, davranış ve yaşam kalitesini iyileştirdiği veya sürdürdüğüne dair genel kanıt kalitesini artırmıştır. Bu kanıtlar biliş odaklı terapi alan hastalarda olası hayal kırıklığı dışında, bu müdahalelerin ilişskili olduğu zararları olmadığını göstermektedir. Bu nedenle, araştırmayı desteklemedeki sınırlamalara rağmen Amerikan Psikiyatri Birliği, kılavuzunda da önerdiği gibi demansı olan bireylerin bakımında ilaç dışı tedavi yöntemlerinin kullanımını desteklemeye devam etmektedir (Rabins et al., 2017).

\section{Anımsama Terapis}

Gerontolog ve psikiyatrist Butler, Erikson'un Psikososyal Gelişim kuramından temel alarak 1963 yılında "Yaşamın Gözden Geçirilmesi (Life Review)" isimli bir çalışma yayımlamıştır. Butler'a göre bilinenin aksine yaşlı bireyin yaşamını tekrar gözden geçirmenin ve geçmişi anımsamanın ilişkilerin iyileştirilmesi açısından çok değerli olduğunu vurgulamıştır (Butler, 1963; Woods et al., 2015). Anımsama terapisinin en açılayıcı tanımı Erikson ve Butler'ın kuramlarından yola çıkarak Bluck ve Levine (1998) "istemli ya da istemsiz olarak bireyin geçmișteki anılarını hatırlaması sürecidir. Unutulmuş ya da unutulmamış, özel ya da genel anılar ve geçmiş deneyimler hatırlandığında gerçeğe yakın duyguların yeniden yaşandığ 
hatırlamanın birebir olabileceği gibi başkalarıyla birlikte de olabileceğidir" șeklinde tanımlamıșlardır. Geçmişi gözden geçirirken sadece geçmişi anımsamak olarak değil, beraberinde geçmişi çözümlemek gerekmektedir. Bu durum amacı olan ve etkin bir süreç olarak ele alınmalıdır. Bu süreçte yaşantıları bütünleştirmek ve yorumlamak gerekmektedir (Lin et al., 2003). Süreç; bireyler, aileler veya gruplarla sosyal boyutta yapilabilmekte ancak geri bildirim verecek profesyonel bir rehber ile yapıldığında geçmişin anlamlandırılması ve yorumlanabilmesi açısından önemlidir. Hatırlamayı kolaylaştırmak için kullanılacak her obje, resim, müzik ya da bir nesne ile anıların tekrar yapılandırılmasına olanak sağlanabilmektedir. Sadece bireysel olarak değil başka bireylerle de grup olarak paylaşılması sosyal etkileşimin de artması açısından yararlı olmaktadır (Lin et al., 2003; Woods et al., 2005).

$\mathrm{AH}$ ve diğer demans türlerine sahip yaşlı bireylerde bilişsel işlev bozuklukları ve depresyon belirtileri yaygın görülmektedir. Yapılan çalışmalar, sistematik derlemeler ve meta-analizlerde, anımsama terapisinin demans ve AH'na sahip yaşlı bireylerde depresyon belirtilerini azalttı̆g 1 , bilişsel işlevleri ve yaşam kalitesini arttırdığı belirtilmiştir (Cuevas et al., 2020; Lök et al., 2019). Park ve arkadaşlarının demanslı bireylere uygulanan anımsama terapisinin etkinliğini inceledikleri metaanalizde (2019), müdahale grubundaki depresyonda görülen demansın davranışsal ve psikolojik belirtilerinin, kontrol grubuna göre anlamlı derecede azaldığını, yaşam kalitesinin ise kontrol grubuna göre önemli ölçüde arttığını bulmuşlardır. Ülkemizde ise Duru Aşiret ve Kapucu tarafindan yapılan çalışmada (2016); müdahale grubundaki bireylerin bilişsel durumundaki artışın ve depresyondaki azalmanın istatistiksel olarak anlamlı olduğunu ancak hareket, bireysel hijyen, beslenme, uyku ve giyinme gibi günlük yaşam aktiviteleri üzerine anımsama terapisinin bir etkisinin olmadığını belirtmişlerdir. Ayrıca, beraberinde grup olarak uygulanan bu uygulamanın iletişim, işbirliği, sosyalleşme ve huzursuzluklar üzerine olumlu bir etkisinin olduğu ifade edilmiştir.

\section{Aromaterapi}

Bitkiler ile tedavi binlerce y1l öncesine kadar uzanan, dünyanın tüm farklı bölgelerinde yetişen bitkilerin sağlık ile ilişkili kullanımı olduğu bilinmektedir. Eski zamanlarda bu bitkiler yakılarak hastalık ve diğer kötülüklerden korunmak için kullanılmıştır. Daha sonraları ise bedene sürülerek veya pomander adı verilen içinde kokulu bitkilerin bulunduğu top şeklindeki kolyeler takılarak hastalıklardan korumak, bedeni güçlendirmek ve güzel kokmak için kullanılmıştır. Modern aromaterapi ise Fransa'da bir kimyager, hekim ve hemşirenin işbirliği ile 1930'lu yıllarda bitkilerden uçucu yağların elde edilmesiyle sağlık alanında kullanılmaya başlanmıştır (Aromaterapi Derneği, 2020).

Aromaterapi (koku molekülleri ile iyileşme); bitki temelli esansiyel yağların fiziksel, zihinsel ve ruhsal etkilerinin iyileştirilmesi için kullanılan destekleyici bir tedavi yöntemidir (Aydin Yildirim \& Kitiş, 2020). Esansiyel yağlar, bireylerin sorunlarını çözmenin yanı sıra özellikle genel bakım için tıbbi ortamlarda uygulanması klinik aromaterapi olarak adlandırılmaktadır. $\mathrm{Bu}$ yağlar, topikal, oral, haricen ve inhalasyon yoluyla kullanılabilmekte ancak en sik topikal ve inhalasyon yollar tercih edilmektedir. Esansiyel yağların vücuda girerek etki etmesinde en yaygın kullanılan topikal yol masajdır. Masaj uygulamasıyla esansiyel yağlar, geniş bir emilim yüzeyi olan deriden kolaylıkla emilmektedir. Masajın başlamasıyla 1020 dakika sonra yağların etkisi kan dolaşımında görülebilmektedir. İnhalasyon yönteminde ise soluma yoluyla vücuda en kolay ve hızlı giriş yolu olarak koku molekülleri beyne ve akciğerlere ulaşabilmektedir. İnhalasyon uygulamasında diffüzör, fan, aromataşı, aroma lambaları, hava nemlendirme cihazları, burun klipsi ve kişisel bant gibi araçlar kullanılabilmektedir (Türten Kaymaz ve Özdemir, 2018).

Birçok kronik hastalıkta uygulandığı gibi demanslı bireylerde de kullanılan aromaterapi, az maliyetli ve yan etkisi olmaması nedeniyle s1k tercih edilen ilaç dışı bir uygulamadır. Demanslı bireylerde sık kullanılan esansiyel yağların başında lavanta ve melisa yağları gelmektedir. Bu bitkilerin sedatize edici etkilerinin yanı sıra biliş düzeyini arttırdığı da yapılan çalışmalarla desteklenmektedir. Demanslı bireylerde lavanta ve melisa yağının farmakolojik etkisinin araştırıldığ bir çalışmada, bu esansiyel yağların ligand kapılı iyon kanallarını etkileyerek ajitasyona karşılık sakinlik verdiği ve sedatize özelliğinin olduğunu saptamışlardır (Huang et al., 2008; Şentürk ve Küçükgüçlü, 2015). Fung ve arkadaşları 2012 yılında yaptıkları sistematik bir derlemede, aromaterapinin demansta görülen davranışsal belirtilere etkilerini incelemiş; aromaterapinin bilişsel işlevselliği iyileştirme ve 
demans hastalarında bilișsel ve davranıșsal belirti sıklıklarını azaltmada olumlu bir etkiye sahip olduğunu ifade etmişlerdir. Ek olarak, günlük yaşam aktivitelerinde, sosyal işlevsellikte ve bağımsılılıta iyileşme bildirmişlerdir. Antipsikotik ilaçlarla karşılaştırıldığında ise aromaterapinin demans hastalarının yaşam kalitesi üzerinde daha iyi bir etkiye sahip olduğu belirtilmiştir. Ülkemizde ise Türten Kaymaz ve Özdemir (2017) demans hastalarında aromaterapinin ajitasyon üzerindeki etkilerini ve bakım verici yükünü değerlendirmişlerdir. Hastaları demans fazlarına ve antipsikotik ilaç alımına göre sınıflandırmışlar ve 14 bireyi müdahale, 14 bireyi ise kontrol grubuna dâhil etmişlerdir. Müdahale grubuna dört hafta boyunca evlerinde masaj ve inhalasyon yoluyla aromaterapi uygulamışlardır. $\mathrm{Bu}$ çalışmanın sonucunda da müdahale grubundaki yaşlı bireylerin nöropsikiyatrik belirtilerinde azalma olduğunu ve bakım verici yükünün artmasının engellendiğini ifade etmişlerdir.

\section{3.Çoklu Duyusal Uyaran Yöntemi}

Çoklu duyusal uyaran yöntemi, demanslı bireylerin bilişsel ve ruhsal belirtilerini azaltmak ve iyilik halini sürdürmek amaciyla görsel, dokunsal, işitsel veya koku uyaranları yoluyla iki veya daha fazla uygulamanın aynı anda kullanılması sonucu ortaya çıkan bir müdahale yöntemidir (Cheng et al., 2019). Bu yöntemin uygulanması için kullanılan yeni tekniklerden biri olan Snoezelen, 1970'lerde Hollanda'da ilk olarak öğrenme güçlüğü çeken bireylerde uygulanmıştır. Müdahaleler, "loş bir şekilde aydınlatılmış, yumuşak bir müziğin duyulduğu oda" olarak tanımlanan özel odada gerçekleştirilmiştir. Özel olarak tasarlanmış bu oda, Snoezelen odası veya çok duyulu uyaran odası olarak da bilinmektedir (Sánchez et al., 2013).

$\mathrm{Bu}$ yöntemin ilaç dışı bir uygulama olarak demanslı bireylerde kullanımı ise 1990'l1 yılların başıdır. Ancak demansı olan yaşlı bireyler duyusal yoksunluk veya tersine aşırı duyusal uyaranlara maruz kalabilmektedir. Bu nedenle çoklu duyusal uyaran yöntemi kullanımında yarar sağlamak isterken olumsuz sonuçların da ortaya çıkma olasılığı bulunmaktadır. Kovach tarafından demansı olan yaşlı yetişkinlerin duyusal uyarıcı veya duyusal sakinleştirici aktivitelerinin hızlanmasındaki dengesizlikler nedeniyle düşünsel rahatsızlıkların yaşanabileceği belirtilmiştir. $\mathrm{Bu}$ düşünsel rahatsızlıklar, ajitasyon davranışlarda artışı içerirken enstrümantal ve sosyal işlevlerde azalmayı içermektedir. Bu nedenle Kovach "sensöristaz" modelini geliştirmiştir. Bu modele göre, demans hastalarına yapılan müdahaleler, duyu uyarıcı ve duyusal sakinleştirici aktiviteler arasında bir denge sağlamak için optimum sensöristazı kolaylaştırmalıdır. Bu bağlamda kullanılacak olan çok sensörlü stimülasyon odası, duyuları uyararak eğlenceli ve stressiz bir ortamın sağlandığ yeterli müdahaleleri oluşturmalıdır (Kovach 2000; Sánchez et al., 2013).

Sánchez ve arkadaşlarının çoklu duyusal uyaran yönteminin demanslı bireylerde uygulanması ile ilgili yaptıkları sistematik derlemede (2013); seanslar sirasinda ve sonrasında demans hastalarının davranışları ve ruh halleri üzerinde kısa vadeli olumlu etkiler olduğunu ancak uzun vadeli yararları üzerine net bir sonuç bulunmadığını ifade etmişlerdir. Aynı çalışmada demanslı yaşlı bireylerde uygulanan bu yöntemin iletişim durumları üzerine yapılmış çok az çalışma olduğunu; bu çalışmalarda da anlamlı ölçüde yararlar sağlanmadığını ancak bakım vericilerin uygulama öncesine nazaran demanslı bireylerde göreceli olarak iletişimin arttığını ifade ettiklerini belirtmişlerdir. Bilişsel olarak incelediklerinde ise çoklu duyusal uyaran yönteminin sadece hafif evre AH'nda düşük de olsa yarar sağlayabileceğini; yöntemin erken evrede uygulanmasının hastalığın ilerlemesini geciktirebileceğini belirtmişlerdir. Ülkemizde ise bu sistematik derlemede de yer alan Özdemir ve Akdemir'in yapmış oldukları çalışmada (2009); hafif evre AH'na sahip huzur evinde kalan 27 yaşl1 bireye dört hafta boyunca haftada üç kez müzik terapi ile nesne ve resim boyama yaptırılmış; ikinci haftadan itibaren mini mental durum değerlendirme puanlarında artış, depresyon ve anksiyete puanlarında ise azalma bulunduğu ve bu puanlar arasında ilişki olduğu ifade edilmiştir.

\section{Fiziksel Egzersiz}

Fiziksel egzersiz; fiziksel uygunluğu iyileştirmek veya sürdürmek için planlı, yapılandırılmış, tekrarlayan ve amaçlanan hareketler olarak tanımlanmaktadır. Yaşlı bireylerin yardım almaksızın yaptıkları aktif fiziksel egzersiz; yürütücü işlevlerini yerine getirebilmelerini sağlamak, sarkopeni riskini ve kas-iskelet zayıflığını azaltmak, esneklik ve düşme riskine karşın denge sağlamak için oldukça önemlidir. Aerobik (tempolu yürüyüş, dans, koşu, bisiklet ve yüzme), dayanıklılık ve direnç (elastik direnç bantları kullanarak lastik topların sıkılması ve ağırlık 
kaldırma), esneklik ve denge (bükme ve germe, tai chi, yoga ve pilates) aktif egzersizleri kapsamaktadır. $\mathrm{Bu}$ aktif fiziksel egzersizlerden aerobik; bireyin beyine giden kan akışını arttırması, dayanıkl11ık ve direnç; kas, tendon ve ligament gücü, kemik yoğunluğu, esneklik, metabolik hız ve postural destek sağlaması, esneklik ve denge ise omuriliği güçlendirme, amaçlı hareket, koordinasyon ve dengeyi geliştirmek için kasları desteklemesi nedeniyle yaşlı bireylere yarar sağlamaktadır. Fiziksel egzersiz genellikle AH ve diğer demansı olan yaşlı bireyler için de önerilmektedir (Park et al., 2020; Sultana et al., 2020).

Bir çalışmada, çeşitli egzersiz türlerinin hafif bilişsel bozukluğu veya hafif demansı olan yaşlı erişkinlerde bilişsel azalmanın önlenmesine veya gecikmesine katkıda bulunabileceği gösterilmiştir (Stephen et al., 2017). McDermott ve arkadaşlarının yaptığ1 sistematik bir derlemede (2019), demans1 olan yaşlı bireyler için egzersizin; fiziksel ve bilişsel işlevler ile günlük yaşam aktiviteleri için yarar sağladığı ancak davranışsal ve psikolojik semptomlar ile ruhsal durumda herhangi bir etki göstermediği belirtilmiştir. Bununla birlikte yeterli yoğunluğa sahip yürüyüş, germe ve diğer kuvvet egzersizleri de dahil olmak üzere çok bileșenli bir egzersizin 12-16 hafta boyunca haftada üç kez ve seans başına 45-60 dakikanın en yararlı sonuçları verdiğini ifade etmişlerdir.

Ancak AH ya da diğer demans türlerine sahip yaşlı bireyler denge, bilişsel bozukluk veya düşme korkusu nedeniyle düzenli egzersize katılmayabilmektedirler. Bu nedenle, ayakta veya yorucu egzersiz yapamayan demanslı yaşlı bireyler için kanıta dayalı, güvenli ve etkili farmakolojik olmayan tedavilere gereksinim olduğu ifade edilmektedir. Park ve arkadaşları yayımladıkları bir çalışmada (2020), ilaç dışı bir yaklaşım olarak, hareket temelli bir zihin-beden terapisi olan sandalye yoga, bir sandalyede otururken veya ayakta destek için sandalyeyi tutarken uygulanan bir yoga tekniğidir. Sandalye yoga; fiziksel durum, nefes alma ve meditasyon/derin gevşemenin bir kombinasyonunu içermekte ve normal yoga ya da egzersize katılamayan demanslı yaşlı yetişkinler için oldukça uygun olduğu düşünülmektedir. Litchke ve arkadaşlarının az sayıda AH olan yaşlı bireylerle yaptıkları araştırmada (2012), hafif $(n=6)$, orta $(n=6)$ ve şiddetli $(n=7)$ olmak üzere üç gruba sandalye yoga uygulaması yapılmış; hafif düzeyde $\mathrm{AH}$ olan bireylerde denge, anksiyete ve bilişte değişiklik gözlenmemiş ancak günlük yaşam aktiviteleri ve depresyon belirtilerinde anlaml iyileşmeler olduğu bildirilmiştir. Bu nedenle erken dönemdeki AH'nın ilerlemesini önlemede ya da yavaşlatmada sandalye yoganın daha fazla yararı olabileceğini belirtmişlerdir.

\section{Ișık Terapisi}

İnsan doğasının en önemli temel gereksinimlerinden birisi de uykudur. Yaşlanmayla birlikte değişiklik gösteren uyku fizyolojisinin yanı sıra AH gibi bazı kronik hastalıkları ve ilaç kullanımlarının etkisiyle uyku hijyeni bozulabilmektedir (Aslan ve Hocaoğlu, 2017). Yaşlılığa ek olarak AH'nın varlığı, hastalık nedeniyle meydana gelen agresyon, ajitasyon, anksiyete ve depresyon gibi psikolojik belirtilerin daha yıkıcı olmasına yol açabilmektedir.

Melatonin salgılanmasını engelleyen 1şık; hipotalamustaki suprakiazmatik çekirdeği (sirkadiyen ritmi kontrol eden bölge), göz ve retinohipotalamik yol ile etkilemektedir. Işı ğın uyku ve uyanıklığın düzenlenmesinde önemli bir faktör olması nedeni ile uyku sorunlarının tedavisinde terapötik olarak uygulanmaktadır. Parlak 1 şık tedavisi, nispeten düşük maliyetli, doğal, basit bir tedavi şeklidir. Ayrıca, ışık terapisi, genellikle ilaç kullanımı ile ilişkili sorunlara yol açmamakta ancak baş ağrısı, göz yorgunluğu, otonom hiperaktivasyon gibi yan etkilere ve hipomaniye neden olabilmektedir (van Maanen et al., 2016).

Işık terapisi, çeşitli deri, sirkadiyen ritim ve zihinsel durumlarla ilgili sorunlar gibi sağlikla ilgili çeşitli sorunların farmakolojik olmayan bir tedavisi olarak kullanılmaktadır. Gün 1şı̆̆ına maruz kalmadan duvara, tavana veya masaya monte edilen cihazlardan, armatürlerden yayılan 1şığa maruz kalmaya kadar çeşitli şekillerde uygulanabilmektedir. Demans ve AH'na sahip yaşl1 bireyler için 1 șık terapisi, serbest çalışan bir biyolojik saati sıfırlamayı, bilişsel davranışı geliştirmeyi ve davranışsal semptomların boyutunu azaltmayı amaçlamaktadır. Yaşlı bireyler üzerinde uygulanan 1 şı terapisinin, yapılan çalışmalar sonucunda kısa ve uzun vadeli olarak; daha kararlı bir uyku-uyanıklık döngüsü, huzursuz ve ajite davranışlarda iyileşme ve bilişsel işlevler üzerinde olumlu etkileri olduğu belirlenmiştir (Aarts et al., 2016).

Sekiguchi ve arkadaşları (2017), farklı demans tiplerine sahip (Alzheimer tipi, vasküler demans ve Lewy cisimcikli demans) uyku sorunları yaşayan 17 
bireyde 1şık terapisinin etkinliğini araştırmışlardır. Çalışmaya katılan demanslı bireyler iki hafta boyunca her gün bir saat boyunca 1şık kutusunun önünde oturmuşlardır. Araştırma bulguları, özellikle hafif ve orta derecede AH olan gruptaki hastaların $(n=8)$ yarısında uyku bozukluğunun iyileştiğini ve ış1k terapisinin demans hastalarının türlerine ve derecelerine bağlı olarak tedavide etkili olabileceğini göstermiştir. Ülkemizde ise Balc1 Alparslan ve arkadaşları (2019), Alzheimer hastalarının ajitasyon, uyku bozukluğu ve gece uykusuzluğu yaşadıklarını belirtmiş ve bu hastalara gündüz fototerapi uygulamıșlardır. Sonuç olarak bu hastaların sirkadiyen ritminin düzenlendiğini; gündüz uykularının azalması nedeni ile günlük yaşam aktivitelerine katılımların arttığını ve geceleri daha etkili uyuduklarını belirtmişlerdir. Forbes ve arkadaşları (2014) ise yaptıkları sistematik analizde uygun aydınlatma yoğunluğunun, sıklığının, aralığının, günün saatinin ve farklı demans tiplerine sahip bireyler için müdahale süresinin belirlenmesinde daha fazla araştırmaya gereksinim olduğunu ifade etmişlerdir.

\section{Müzik Terapisi}

Müzik terapisi, geçmişte birçok kültürde hastaları tedavi etmek ve rehabilitasyonu sağlamak amacıyla sık kullanılmıştır. Özellikle bireyin duygu ve düşüncelerine etki eden müziğin kendine özgü anlatımı olduğu düşünülmüştür. Günümüzde de aynı etkilere sahip olduğu düşünülen müzik, Alzheimer hastalarının nörolojik sistemine olumlu etkiler yapmakta, bireylerin duygu ve düşüncelerinde anlamlı tepkilerin ortaya çıkmasını kolaylaştırmaktadır (Kıyak, 2019). Yapılan farklı araştırmalarda, müziğin; ruhsal hastalıkların oluşumunda etkisi olan serotonin, dopamin, adrenalin, testosteron gibi hormonları düzenlemesi sonucu bireyin duygu durumunu olumlu etkilediği, beyindeki oksijen ve kanlanmayı dengeleyerek kan basıncı ve solunum hızı gibi yaşamsal bulguların en uygun düzeyde kalmasını desteklediği gözlenmiştir. $\mathrm{Bu}$ nedenle de müziğin Alzheimer hastalarının özellikle ruhsal belirtilerinde azalmalara neden olduğu düşünülmektedir (Lök ve Bademli, 2016; Ridder \& Gummesen, 2015).

Müzik terapisini eğitim ve eğlenceyle karşılaştıran bir çalışma, müzik terapisi grubunun sanr1, ajitasyon, kayg1, ilgisizlik, sinirlilik düzeylerinin kontrol grubuna göre daha düşük olduğunu ve uyku rahatsızlığını daha az yaşadığını ifade etmiştir (Raglio et al., 2008). Demansı olan huzurevi sakinleri için bireysel müzik terapisinin ajitasyonu azalttı̆g 1 ve psikotropik ilaç kullanımının azaltımına yardımcı olduğu gösterilmiştir (Ridder et al., 2013). Özellikle demanslı huzurevi sakinlerinin müzik tabanlı programlara katılması, hareket, ritim ve şark1 söyleme gibi aktivitelerle sosyal firsatlar sunmas1 nedeniyle ajitasyon ve depresyon belirtilerinin azalmasına yol açabileceği düşünülmektedir (Ridder \& Gummesen, 2015).

\section{Sonuc}

AH'nın kesin bir tedavisinin olmaması, özellikle tanılanmadan sonraki dönemde etkili bir ekip yaklaşımını gerektirmektedir. Ekibin amacı, yaşı bireyin olabildiğince uzun süre bağımsız bir yaşam sürdürmesini, hastalığın ilerlemesini geciktirmeyi, komplikasyonları önleyerek hastaların ve ailelerinin yaşam kalitesini arttırmaktır. Bu açıdan en önemli ekip üyelerinden biri olarak hemşirelerin temel amac1, temel yaşam faaliyetlerini sürdüremeyen bireylere yardımcı olmak ve yol göstermektir. Bu bağlamda ilaç tedavilerinin yanı sıra uygulanacak ilaç dıșı yöntemler, maliyetin az olmasının yanı sıra herhangi bir zararının olmaması açısından da kullanılması oldukça yarar sağlayabilmektedir. Ancak bu ilaç dıșı müdahalelerin uzun vadeli etkisinin bilinmemesi ile birlikte uygulamaların süresi, ne kadar süreyle kaç kez uygulanacağı gibi değişkenler konusunda net bir kanıt sunulamadığı için bu konularda daha çok araştırmaya gereksinim duyulmaktadır. Hastalık yükünün ve belirtilerin azaltılmas1, komplikasyonların önlenmesi, hastalığın geciktirilmesi ve bireyin yaşam kalitesinin artırılması için bu destekleyici müdahalelerin rutin hemşirelik bakımına dâhil edilmesinin hasta, bakım verici ve sağlık ekibi için yararlı olacağı düşünülmektedir.

Araștırmanın Etik Yönü/ Ethics Committee Approval: Literatür incelemesi yapılmış ve atıf yapılan literatür kaynaklar bölümünde gösterilmiştir.

Yazar Katkısı/Author Contributions: Fikir/ kavram: $\mathrm{CB}, \mathrm{AK}$; Tasarım: CB, AK; Veri toplama ve/veya Veri İşleme: CB; Analiz ve/veya Yorum; CB, AK; Kaynak tarama: CB; Makalenin yazımı: CB; Eleştirel İnceleme: $\mathrm{AK}$.

Çıkar çatışması/Conflict of interest: Çalışmada herhangi bir çıkar çatışması yoktur.

Finansal Destek/Financial Disclosure: $\mathrm{Bu}$ çalışma herhangi bir kurum ya da kuruluş tarafından desteklenmemiştir. 


\section{Çalışma Literatüre Ne Kattı?}

- Alzheimer Hastalığında uygulanan ilaç dış1 uygulamaların neler olduğu açıklanmıştır.

- Alzheimer Hastalığı için alanda çalışan hemşirelere ve diğer sağlık profesyonellerine güncel yaklaşımlar sunmaktadır.

\section{Kaynaklar}

Aarts MPJ, Aries MBC, Diakoumis A, Van Hoof J. (2016). Shedding a light on phototherapy studies with people having dementia: a critical review of the methodology from a light perspective. American Journal of Alzheimer's Disease \& Other Dementias, 31(7), 551-563.

Alzheimer's Association. (2020). Alzheimer's Association 2020 Facts and Figures Report. Erișim Tarihi: $\quad 02 \quad$ Haziran 2020 https://www.alz.org/alzheimers-dementia/factsfigures\%0Ahttps://www.alz.org/media/Documents/al zheimers-facts-and-figures_1.pdf

Alzheimer's Association. (2018). Alzheimer's Disease Facts And Figures. Alzheimer's \& Dementia, 14(3), 367-429.

Aromaterapi Derneği. (2020). Erișim Tarihi: 05.06.2020, http://www.aromaterapidernegi.com/

Amin F, et al. (2019). Alzheimer's: a progressive brain disease: causes, symptoms, and prevention in Biological, diagnostic and therapeutic advances in Alzheimer's disease: non-pharmacological therapies for Alzheimer's disease (Ashraf G, Alexiou A. eds.), Springer Singapore, p. 41-44.

Aslan M, Hocaoğlu C.. (2017). Yaşlanma ve yaşlanma dönemiyle ilişkili psikiyatrik sorunlar. Düzce Üniversitesi Sağlık Bilim Enstitüsü Dergisi, 7(1), 53 62.

Aydin Yildirim T, Kitis Y. (2020). The effect of aromatherapy application on cognitive functions and daytime sleepiness in older adults living in a nursing home. Holistic Nursing Practice, 34(2), 83-90.

Balcı Alparslan G, Özkaraman A, Özbabalık D, Çolak E. (2019). The effect of light on daily life activities and sleep in patients with Alzheimer's Disease. Journal of Turkish Sleep Medicine, 3, 59-64.

Bluck S, Levine LJ. (1998). Reminiscence as autobiographical memory: a catalyst for reminiscence theory development. Ageing and Society, 18(2), 185208.

Butler RN. (1963). The Life Review: an interpretation of reminiscence in the aged. Psychiatry (New York), 26(1), 65-76.

Centers For Disease Control And Prevention. (2017). Erişim Tarihi: 02.06.2020, https://www.cdc.gov/aging/aginginfo/alzheimers.htm \#burden
Cheng C, Baker GB, Dursun SM. (2019). Use of multisensory stimulation interventions in the treatment of major neurocognitive disorders. Psychiatry and Clinical Psychopharmacology, 29(4), 916-921.

Cuevas PEG, Davidson PM, Mejilla JL, Rodney TW. (2020). Reminiscence therapy for older adults with Alzheimer's disease: A literature review. International Journal of Mental Health Nursing, 29(3), 364-371.

Duru Așiret G, Kapucu S. (2016). The effect of reminiscence therapy on cognition, depression, and activities of daily living for patients with Alzheimer Disease. Journal of Geriatric Psychiatry and Neurology, 29(1), 31-37.

Forbes D, Blake CM, Thiessen EJ, Peacock S, Hawranik P. (2014). Light therapy for improving cognition, activities of daily living, sleep, challenging behaviour, and psychiatric disturbances in dementia. Cochrane Database of Systematic Reviews, (2). doi:10.1002/14651858.CD003946.pub4

Fung JKK, Tsang HWH, Chung RCK. (2012). A systematic review of the use of aromatherapy in treatment of behavioral problems in dementia. Geriatrics \& Gerontology International, 12(3), 372382.

Huang L, Abuhamdah S, Howes MJR, Dixon CL, Elliot MS, Ballard C, et al. (2008). Pharmacological profile of essential oils derived from Lavandula angustifolia and Melissa officinalis with anti- agitation properties: Focus on ligand- gated channels. Journal of Pharmacy and Pharmacology, 60(11), 1515-1522.

Keogh F, Mountain G, Joddrell P, Lord K. (2019). Psychosocial interventions for community-dwelling people following diagnosis of mild to moderate dementia: findings of a systematic scoping review. The American Journal of Geriatric Psychiatry, 27(6), 641-651.

Kıyak M. (2019). Alzheimer hastalarında müziğin uyum güçlüğünü azaltmadaki etkisi. Yayımlanmamış Yüksek Lisans Tezi. Osmangazi Üniversitesi Sağlık Bilimleri Enstitüsü, Eskişehir.

Kovach CR. (2000). Sensoristasis and imbalance in persons with dementia. Journal of Nursing Scholarship, 32(4), 379-384.

Lin Y-C, Dai Y-T, Hwang S-L. (2003). The effect of reminiscence on the elderly population: a systematic review. Public Health Nursing, 20(4), 297-306.

Litchke LG, Hodges JS, Reardon RF. (2012). Benefits of chair yoga for persons with mild to severe Alzheimer's disease. Activities, Adaptation \& Aging, 36(4), 317-328.

Lök N, Bademli K, Selçuk- Tosun A. (2019). The effect of reminiscence therapy on cognitive functions, depression, and quality of life in Alzheimer patients: randomized controlled trial. International Journal of Geriatric Psychiatry, 34(1), 47-53. 
Lök N, Bademli K. (2016). Effectiveness of music therapy in Alzheimer patients: Systematic review. Psikiyatride Guncel Yaklasimlar-Current Approaches in Psychiatry, 8(3), 266-274.

McDermott O, Charlesworth G, Hogervorst E, Stoner C, Moniz-Cook E, Spector A, et al. (2019). Psychosocial interventions for people with dementia: a synthesis of systematic reviews. Aging \& Mental Health, 23(4), 393-403.

Ozdemir L, Akdemir N. (2009). Effects of multisensory stimulation on cognition, depression and anxiety levels of mildly-affected alzheimer's patients. Journal of the Neurological Sciences, 283(1-2), 211-213.

Park J, Howard H, Tolea MI, Galvin JE. (2020). Perceived benefits of using nonpharmacological interventions in older adults with alzheimer's disease or dementia with lewy bodies. Journal of Gerontological Nursing, 46(1), 37-48.

Park K, Lee S, Yang J, Song T, Hong GRS. (2019). A systematic review and meta-analysis on the effect of reminiscence therapy for people with dementia. International Psychogeriatrics, 31(11), 1581-1597.

Rabins PV., Rovner BW, Rummans T, Schneider LS, Tariot PN. (2017). Guideline Watch (October 2014): practice guideline for the treatment of patients with Alzheimer's disease and other dementias. Focus (Madison), 15(1), 110-128.

Raglio A, Bellelli G, Traficante D, Gianotti M, Ubezio MC, Villani D, et al. (2008). Efficacy of music therapy in the treatment of behavioral and psychiatric symptoms of dementia. Alzheimer Disease \& Associated Disorders, 22(2), 158-162.

Ridder HM, Gummesen E. (2015). The use of extemporizing in music therapy to facilitate communication. Australian Journal of Music Therapy, 26(3), 148-173.

Ridder HMO, Stige B, Qvale LG, Gold C. (2013). Individual music therapy for agitation in dementia: An exploratory randomized controlled trial. Aging \& Mental Health, 17(6), 667-678.

Sahyouni R, Verma A, Chen J. (2016). Alzheimer's disease decoded: The history, present, and future of Alzheimer's disease and dementia. In Alzheimer's Disease decoded: the history, present, and future of Alzheimer's Disease and Dementia. doi: 10.1142/10023

Sánchez A, Millán-Calenti JC, Lorenzo-López L, Maseda A. (2013). Multisensory stimulation for people with dementia: a review of the literature. American Journal of Alzheimer's Disease \& Other Dementias ${ }^{\circledR}, 28(1)$, 7-14.

Sekiguchi H, Iritani S, Fujita K. (2017). Bright light therapy for sleep disturbance in dementia is most effective for mild to moderate Alzheimer's type dementia: a case series. Psychogeriatrics, 17(5), 275 281.
Selekler K. (2010). Alois Alzheimer ve Alzheimer Hastalığı. Türk Geriatri Dergisi, 13(3), 9-14. http://geriatri.dergisi.org/text.php3?id=508

Stephen R, Hongisto K, Solomon A, Lönnroos E. (2017). Physical activity and Alzheimer's Disease: a systematic review. The Journals of Gerontology. Series A, Biological Sciences and Medical Sciences, 72(6), 733-739.

Sultana M, Bryant D, Orange JB, Beedie T, MonteroOdasso M. (2020). Effect of Wii FitC Exercise on balance of older adults with neurocognitive disorders: a meta-analysis. Journal of Alzheimer's Disease, 75(3), 817-826.

Şentürk SG, Küçükgüçlü Ö. (2015). Aromaterapi Uygulamasının Demanslı Bireylerde Görülen Davranışsal Değişiklikler Üzerine Etkisi. Dokuz Eylül Üniversitesi Hemşirelik Fakültesi Elektron Dergisi, 8(3), 190-194.

Turten Kaymaz T, Ozdemir L. (2017). Effects of aromatherapy on agitation and related caregiver burden in patients with moderate to severe dementia: A pilot study. Geriatric Nursing (Minneap), 38(3), 231-237.

Türkiye İstatistik Kurumu [TÜİK]. (2017). Erişim Tarihi: 02.06.2020, www.tuik.gov.tr

Türten Kaymaz T, Özdemir L. (2018). Demansl Bireylerin Ajitasyon Yönetiminde Aromaterapinin Kullanımı. Düzce Üniversitesi Sağlık Bilimleri Enstitüsü Dergisi, 8(3), 147-150.

van Maanen A, Meijer AM, van der Heijden KB, Oort FJ. (2016). The effects of light therapy on sleep problems: a systematic review and meta-analysis. Sleep Medicine Reviews, 29, 52-62.

Woods B, Spector A, Jones C. (2005). Reminiscence therapy for dementia. The Cochrane Database Systematic Review. 2005(2):CD001120.

World Alzheimer Report. (2015). Alzheimer's Disease International. Erișim Tarihi: 02 Haziran 2020, https://www.alz.co.uk/research/WorldAlzheimerRep ort2015.pdf 